\title{
Organizational Turning Points: The Transformation of the Almighty Latin King and QueEn Nation in New York CITY
}

\author{
LUCA BERARDi
}

SANDRA M. BUCERIUS

\begin{abstract}
Sociologists and criminologists have relied on the concept of "turning points" to map individual criminal careers over the life course. Similar to individuals, criminal organizations undergo drastic changes that influence their trajectory over time and space. Using the case of the Almighty Latin King and Queen Nation (ALKQN) in New York City, we introduce the concept of "organizational turning points" to explain the group's evolution through various legitimate and illegitimate forms. Bringing together conceptual lenses from literature on organizational change, culture and cognition, and criminology, we demonstrate that street gangs can be complex and fluid organisms that change over time and space. Identifying and recognizing organizational turning points in criminal groups can have important implications for scholars and practitioners alike.
\end{abstract}

Keywords: gangs; organizational turning points; Almighty Latin King and Queen Nation

Résumé. Au cours de la vie, les sociologues et criminologues se sont appuyés sur le concept des « points tournants » pour tracer les carrières criminelles individuelles. Semblable aux individus, les organisations criminelles subissent des changements drastiques qui influencent leur trajectoire à travers l'espace et le temps. À l'aide du cas de l'Almighty Latin King and Queen Nation (ALKQN) à la ville de New York, nous présentons le concept de «points tournants organisationnels " pour expliquer l'évolution du groupe à travers des formes légitimes et illégitimes variées. En rassemblant des visions conceptuelles provenant de la littérature sur le changement organisationnel, la culture et la cognition, et la criminologie, nous démontrons que les gangs de rue peuvent être des organismes complexes et fluides qui changent au cours du temps. L'identification et la reconnaissance des « points tournants organisationnels » dans les groupes criminels 
peuvent avoir des implications importantes tant aux érudits qu'aux praticiens.

Mots clés: gangs; points tournants organisationnels; l'Almighty Latin King and Queen Nation

\section{INTRODUCTION}

$\mathrm{M}$ ost research on gangs has focused on the socio-economic conditions under which these groups emerge (Sanchez-Jankowski 2003; Vigil 2003) and their subsequent impact on crime, violence, and illicit markets (Decker and Van Winkle 1996; Venkatesh 1997). These analyses provide interesting snapshots into the characteristics of gangs at particular moments in their life cycle. Few studies, however, have examined how and why street gangs transform across time and space. Like gang members who sway between deviance and conformity (Venkatesh 2000), street gangs can oscillate between illegitimate and legitimate identities.

Many contemporary gang studies overlook the social, cultural, and political factors that shape the trajectories of modern street gangs (for recent exceptions, see Kontos et al. 2003; Brotherton and Barrios 2004; Brotherton 2015; Fraser 2015); more troubling, scholarship has largely ignored how these groups attempt to remain relevant against such everchanging backdrops. Being mindful of these shortcomings, we argue that contemporary street gangs must be understood as living organisms, sensitive to changes in their environment. ${ }^{1}$ Like the members that fill their ranks, street gangs can and do transform across time and space. With enough cultural stimuli (Carrillo and Gromb 2007), they can morph into legitimate organizations, rebranding themselves as activists and working with state and local institutions for lawful initiatives (Pattillo 1998; Venkatesh 2008; Papachristos et al. 2013).

1. Implicitly or explicitly, contemporary research on street gangs tends to depict these groups as static entities--fixed within a particular socio-spatial location and largely resistant to internal and external pressures. The focus of analysis is often the impact of gang membership on gang members. Rarely is the unit of analysis "the gang" itself. Our experience is that these groups are not, as often depicted, silos of stability, impermeable to historical events or the happenings of everyday life; rather, they are constantly adapting, transitioning, resisting, and conforming. Like Brotherton (2015: 40), we believe that, "Gangs are powerful indicators of the contradictions of the larger society and if we $[. .$.$] study them [\ldots]$ separate from the cross-cutting tensions that mirror their development in the community, or fail to take into account their evolution over time and across space, then we are likely to produce findings and draw conclusions that simply mirror the prejudices and pathological gazes of the dominant social order." 
Our study examines the history and trajectory of the Almighty Latin King and Queen Nation (ALKQN or Nation), one of the most notorious, highly structured, and ideologically driven street gangs in the United States and abroad. The ALKQN has been involved in drug dealing, extortion, fraud, and violence, including murder (Knox 2000; DeKeseredy and Dragiewicz 2011). Over the years, the New York City (NYC) chapter of the ALKQN, ${ }^{2}$ which is the primary focus of our analysis, has tried to reconcile this image by undertaking a massive transformation from street gang to cultural organization - presenting itself as a positive force in the Latino community (Curtis 2003). Although the NYC chapter is not the only branch to move away from its street gang image and tendencies - chapters in Spain (Feixa et al. 2008) ${ }^{3}$ and Italy (Palmas 2010) were also recognized as a legitimate cultural organization for quite some time - it provides the clearest example of a gang experiencing multiple transitions.

To our knowledge, the criminological literature has not offered a coherent theoretical explanation for how and why some street gangs transform into legitimate enterprises. While not focused on illicit groups, organizational sociologists (e.g., Dezalay 1990; Sauder and Espeland 2009) have documented some of the factors leading to organizational change (or lack thereof) in a variety of institutional settings. Kellogg (2009), for example, finds that organizational change - in this case, a mandated reduction in weekly work hours for surgical residents at U.S. teaching hospitals - was being ignored by surgical residents because mid-level managers were not fully supportive of the change. Kellogg shows that it takes more than a mandated policy to alter the daily practices and culture of an organization. Organizational sociologists have also analyzed the types of business models that emerge when organizational change occurs (e.g., Dobbin and Dowd 2000).

While sociologists have analyzed organizational change (or resistance to it), they have not explored the role of "organizational turning points" as motivations for these transitions. Similarly, while criminologists have focused on turning points for individuals, they have been silent on how and why criminal organizations transform over time and space. To bridge this gap, we introduce the concept of "organizational turning points"-i.e., key moments or events in the life course of an organization or group that facilitate, or cause, rapid and dramatic shifts from its previous trajectory.

The "turning point" is a key concept in research on the life course, with literature focusing on individuals and their long-term develop-

2. Groupings of the ALKQN in different localities are referred to as "chapters."

3. The reorganization as cultural organization ultimately failed and, today, the ALKQN is seen as Spain's most notorious Latino gang (Calvo 2015). 
mental patterns as they relate to changing social roles-e.g., graduating from college, meeting a spouse, becoming a parent (Hser et al. 2007). In criminology, turning points have become central foci of developmental criminologists interested in criminal careers (Benson 2001; Sampson and Laub 2005). Sampson and Laub (1993: 351), for example, describe life trajectories as "long term patterns and sequences of behavioral transition" that are shaped by the social capital available to an individual; these trajectories can be interrupted or changed by a transition, i.e., changes to an individual's social role, as described above. According to Sampson and Laub (1993), some (though not all) of these transitions will lead to "turning points," which will subsequently initiate long-term change (Teruya and Hser 2010). We argue that, similar to individuals, street gangs can and do transform, even if these transformations are not permanent. These transformations can be initiated by shifts in organizational structure, brought on by shifts in the local context (e.g., social and economic exclusion, the birth or death of a drug market, prison experiences, connections to other institutions), the induction or removal of a charismatic leader, or some combination thereof (see, for example, Contreras' (2013) account of a street gang's evolution from a drug dealing to drug robbing organization in response to the decline of crack cocaine).

In this article, we bring together and deploy conceptual lenses from literature on organizational sociology, culture and cognition, and criminology to analyze the trajectory of the NYC chapter of the ALKQN. We trace its evolution from a cultural organization, to a violent prison and street gang, to a legitimate street movement, to its most current stateone that is seemingly ambiguous and muddled. To do this, we rely on a combination of hundreds of pages of court documents (acquired by one of the authors who served as an expert witness for a criminal case involving the ALKQN in Toronto) and the few published academic works on the group (e.g., Curtis 2003; Martinez 2003; Brotherton and Barrios 2004; Brotherton 2015). In particular, we read and analysed all documents that were provided to the author who served as an expert witness, including the ALKQN's Manifesto, Constitution, meetings minutes, police reports, and demographics of the Toronto chapter. We contextualize these data with our own observational data (approximately nine months of fieldwork in NYC and Genoa, Italy ${ }^{4}$, as well as numerous professional conversations and exchanges with ethnographers who have con-

4. One of the authors worked as a research assistant on a project involving the ALKQN. The principal investigators of that study, who are not co-authoring this article, own those data. Therefore, we only draw on those research experiences indirectly - i.e., to help us better contextualize our understanding of the group and the events surrounding its transformation. 
ducted fieldwork with the NYC chapter. We unpack how and why the ALKQN adopted particular structural forms and lines of action over its life course by deploying concepts that, traditionally, have not been used to understand street gangs.

We do this by outlining our definition of "organizational turning points" to account for rapid and dramatic shifts in criminal organizations and groups. We then provide an overview of the ALKQN's birth in Chicago and its expansion to NYC. We go on to analyze the different stages of development and evolution within the ALKQN in NYC. What will become evident is that contemporary street gangs such as the ALKQN are not static enterprises (see Venkatesh 1997; Coles 2001), but complex and fluid organisms; under the right conditions, they can and do transform, capitalizing on turning points to align themselves more closely with conventional society - mimicking and conforming to, not resisting, mainstream institutions. This study has important implications for how scholars and law enforcement agencies should think about gangs. Standard tactics used by law enforcement may actually impede a gang's effort to transition into a legitimate organization and, as in the case of the NYC chapter of the ALKQN, actually contribute to its regression back into a criminal enterprise.

\section{Organizational Turning Points}

While organizational change and individual turning points have been discussed in the scholarly literature, these two bodies of work have never been integrated to account for turning points in the life course of an organization - in this case, a criminal group. Importantly, we draw distinctions between "organizational change" and "organizational turning points," despite the fact that both can lead to similar outcomes. Organizational change is the sum of multiple (often micro-level) decisions made by an organization over a significant period of time, resulting in an overall shift in its direction, structure, and/or purpose. Organizations can also initiate these sorts of changes at the macro-level by reflecting on past trends (e.g., by analyzing whether a given trajectory has been successful, however defined) and by making projections about the future (e.g., by determining whether a new direction is necessary, given changing trends); over time, decisions based on these considerations, among other things, will steer an organization in a particular direction, shaping its future structure, mandate, and culture.

These organizational changes can be a response to internal shifts or external pressures from the market. A street gang, for example, may gradually transition from ethnically homogenous to heterogeneous as a 
result of changing neighbourhood composition over the span of years or decades (Knox 2000). It may enter or exit particular drug markets depending on the popularity of a substance at a particular moment in time. Street gangs have been known to transform in response to these long-term trends and changes to demand (Bucerius 2014).

Organizational turning points, on the other hand, are the result of sudden changes in the operational field (Emirbayer and Johnson 2008), which provide ideal conditions for a dramatic shift in the purpose, direction, and/or practices of an organization. A major event (often amplified and followed by powerful aftershocks) can shake the foundation of an otherwise concrete and established organization, providing an opportunity for it to deviate from its previous trajectory. For this to occur, however, the event that sparks a potential turning point must be taken-on or exploited by actors (e.g., a new leader or a subset of members) capable of moving an organization in a new direction. As will become apparent, the sudden arrest of a violent gang leader (King Blood) created space for a new charismatic leader (King Tone) to radically alter the direction of the NYC chapter of the ALKQN, from street gang to street movementfrom an illegitimate group to a legitimate cultural organization. In this way, turning points that occur in the lives of individuals - typically those with power or in a position to usurp it - can serve as the foundation of a turning point at the organizational level, ultimately directing the group away from its previous trajectory and towards a new direction.

The idea of organizational turning points serves as the framework of our analysis, and we highlight these key moments in the history of the ALKQN in NYC. While the concept of organizational turning points helps us understand why this group experienced such dramatic shifts in its trajectory, the sociological literature on organizations and on culture and cognition helps us understand how those shifts actually occurred.

\section{Street Gang: The Emergence of the Alkqn in Chicago \& NYC}

The first chapter of the Latin Kings emerged in Chicago between 1940 and the late 1960s (Feixa et al. 2008; Brotherton 2013). ${ }^{5}$ In its earliest manifestation, the group functioned as a "cultural shock absorber," assisting Latino immigrants integrate into city life. Flood (2003: 246)

5. There is little consensus about when the group was founded. Some suggest that it emerged in the Illinois prison system during the late 1940s, others argue that it was an offshoot of a 1950s group and became the Latin Kings in the 1960s, still others suggest that there is no evidence of the Latin Kings existing before 1965 (Brotherton 2013: 237). 
notes that, "the group distributed communal property such as household items, clothing, and emergency funds. The members also assisted each other with housing, employment, educational and language barrier needs, while at the same time offering an umbrella of protection against racial violence and police repression through solidarity and informal social activities." Despite living in relatively poor socio-economic conditions, the group displayed high levels of collective efficacy (Sampson et al. 1997) - tightly connected to the Latino community, enthusiastic to help integrate members into Chicago, and willing to fight on their behalf if necessary.

In this early stage, the Latin Kings lacked many of its contemporary characteristics, such as its highly organized and hierarchical structure, its coherent ideology, or its strong socio-political consciousness. Yet, even in its primitive form, criminality was part of group life. With little access to legitimate opportunities (Merton 1938), the group used criminal activities to establish the Latino community within Chicago, both economically and socially. At this stage, the group did not identify as criminal, nor did outsiders consider it a street gang (Knox 2000). Rather, crime was understood as an economic necessity and was neutralized as such (Sykes and Matza 1957). In many ways, the group served the function of an ethnic enclave (Portes and Schafer 2006), providing support and resources to in-group members, with this end justifying its criminal means.

By the mid-1960s, the poor socio-economic conditions faced by barrio residents were exacerbated by the sudden influx and demand of illicit drugs (Block and Block 1993). The Latin Kings capitalized on this opportunity, becoming the largest and most violent Latino street gang in Chicago and a major player in the city's drug trade (Block and Block 1993). This dramatic shift from cultural shock absorber to criminal enterprise occurred over time - a result of changes to the drug market and a growing opportunity for Latinos to climb the socio-economic ladder. Consequently, this period marks an organizational "change" in the life course of the Nation, as opposed to an organizational "turning point."

The shift towards the illicit market pushed the Latin Kings to make structural and ideological modifications: the leaders created the King's Manifesto, which outlined the ideology and overall purpose of the group (i.e., "Kingism" and the empowerment of the Latino community, respectively); they put together the King's Constitution, which governed the daily activities and practices of members, and; they violently enforced both the Manifesto and Constitution within their ranks. ${ }^{6}$ In short, the Manifesto documents, in writing, the aims and ideologies of the Latin

6. Unless otherwise stated, all information about the King's Manifesto (ideology, purpose, etc.) and King's Constitution (rules, laws, procedures, sanctions, etc.) are taken directly from the documents themselves. 
Kings. It emphasizes the empowerment of the Latino people, stating, "The ALKQN is a religion which gives us faith in ourselves, a national self-respect, a power to educate the poor, and relieve the misery around us." Yet, the Manifesto also accounts for criminal activity, which is built directly into the ideology of "Kingism" - an ideology which states that members will move from a stage of "immaturity and crime" to "enlightenment and empowerment" as part of their natural development into productive members of the Latino community (Barrios 2003).

A number of economists (see Leeson 2007; Leeson and Skarbek 2010; Leeson and Rogers 2012) have found that some of the most successful illicit organizations - be it street gangs, pirate crews, or mafia clans - utilize detailed and codified criminal constitutions to minimize internal predation and intra-group conflict, thus increasing their likelihood of maximizing profits. It should not be surprising, therefore, that by the mid-1980s, the ALKQN had spread across the country, becoming one of the largest and most successful street gangs in the U.S. While predominately Latino-based, the ALKQN also included members of different racial and ethnic groups, depending on local context and leadership. All chapters, however, follow the King's Manifesto and Constitution and operate under similar leadership structures. Aside from the Chicago "Motherland" chapter, the most powerful and influential is the "Bloodline" chapter in NYC.

The history of the NYC chapter begins in 1986, when Luis Felipe (known as "King Blood"), a member of the Motherland chapter, fled to New York to avoid imprisonment for crimes committed in Chicago (Richardson 1997). Soon after his arrival, he was arrested and subsequently convicted of murdering his former girlfriend and sentenced to the Collins Correctional Facility in New York State (Brotherton and Barrios 2004; Feixa et al. 2008). While incarcerated, King Blood identified a need for a Latino-based prison gang. He formed his own chapter of the ALKQN, known as the "Bloodline," and designated himself Inca and Supreme Crown of New York (Brotherton 2013). The NYC chapter emerged under similar conditions as the Chicago chapter decades earlier - out of a need to support and protect Latinos, albeit this time within the carceral setting.

Given the constant threat of harassment and assault at the hands of guards and other ethnic gangs, King Blood formed the Bloodline chapter as a protection mechanism for Latinos within the prison system (see Gundur (2020) for a detailed analysis of Barrio Azteca's similar progression from prison solidarity group to criminal organization). King Blood drafted the New York State Manifesto and adopted, almost verbatim, the teachings, principles, and structure of the Motherland chapter (Brotherton and Barrios 2004). In its early stages, then, the NYC chapter was 
predominantly prison-based and mimicked the structure and many of the principles of the Chicago Motherland.

DiMaggio and Powell's (1983) analysis of isomorphic tendencies within organizational fields provides a theoretical lens for understanding this mimetic process. They argue that distinct organizations operating within a particular field often converge and begin to look and act like each other over time. This is due to what they call isomorphism, "a constraining process that forces one unit in a population to resemble other units that face the same set of environmental conditions" (DiMaggio and Powell 1983: 149). In uncertain and unsettled times, "mimetic isomorphism" occurs as, "organizations tend to model themselves after similar organizations in their field that they perceive to be more legitimate or successful" (DiMaggio and Powell 1983: 152). Under the lens of mimetic isomorphism, King Blood's wholesale adoption of the ALKQN brand, ideology, and purpose becomes more intelligible. The uncertainty associated with creating a new gang in the prison system, coupled with the urgency for protection, pushed King Blood to mimic the structure and practices of the Chicago Motherland - a reputable and well-established cultural organization turned street gang with which he was intimately familiar.

With the release of large numbers of Latino inmates in the early 1990s, the ALKQN's street presence in NYC began to swell (Tabor 1994; Kontos 2012). While maintaining its protective function within the prison system, members on the outside started teaching the principles of the King's Manifesto on the streets. When King Blood was released from prison in 1994, an internal power struggle erupted within the NYC chapter. Ultimately, seven Latin Kings were killed (along with one outsider) and King Blood, along with nineteen other members, were indicted on charges of murder and racketeering (Kontos 2012). King Blood received the harshest federal sentence handed down since World War II-250 years of imprisonment, with the first forty-five years to be spent in solitary confinement. By 1995, thirty-eight Kings and one Queen (the female branch of the Nation) were indicted under the RICO Act, with an average sentence of twenty years. Commenting on this internal power struggle, Brotherton and Barrios (2004: 140) posit that:

The competition in the upper strata of the gang is not unlike the intrigues found among many mainstream bureaucratic organizations at the highest level. In politics, in business, and in academia, the factional fighting, the conspiracies, the purges, the coups, are all present in the ongoing struggle between personalities, visions, and ideologies within the same organization. The big difference, however, is the propensity of the Latin Kings to use violence to settle disputes. 
Finding it increasingly difficult to direct the NYC chapter in solitary confinement, King Blood crowned Antonio Fernandez (known as "King Tone") as Supreme Crown and Inca of New York State and New Jersey in 1995 (Kontos 2012). During this period of changing leadership, the demographic makeup of the Nation also began to change. While continuing to accept former convicts, the NYC chapter also began to appeal to and accept more politically attuned members-young and poised Latinos who shared a desire to better themselves and their culture. Conscious of this demographic shift, King Tone reassessed the purpose and ideology of the Nation by canvassing the needs and desires of his new members, setting the group on a new trajectory-away from its street gang image towards a legitimate and politically-driven street organization (Brotherton and Barrios 2004). This drastic transformation marks the first organizational turning point for the NYC chapter, facilitated by the timely incarceration of King Blood and the subsequent appropriation of leadership by King Tone.

\section{Transforming from Street Gang to Street Movement}

As the newly crowned Inca of New York State, King Tone immediately began transforming the Bloodline chapter. In a public announcement, he proclaimed that, "the group had lost its way, that it had been led astray in the underworld and it was now time for the ALKQN to reclaim direction and purpose" (Kontos 2012: 111). His first official order as Supreme Crown was telling of this new direction - the NYC chapter was to renounce its violent past so that it might have a future. In line with this, the group adopted a relatively coherent and positive ideology and purpose - empowering the Latino community through education, vocational training, and political representation and activism (Brotherton and Barrios 2004). The works of Burt (2004) and Zerubavel (1997) help shed light on how King Tone managed to spark this unusual transformation.

Burt (2004) examines brokerage across groups. He maintains that, "Opinion and behavior are more homogenous within than between groups, so people connected across groups are more familiar with alternative ways of thinking and behaving, giving them more options to select and synthesize. New ideas emerge from selection and synthesis across the structural holes between groups" (Burt 2004: 350). The concept of brokerage is useful for understanding how the NYC chapter transformed, albeit temporarily, from a criminal street gang to a legitimate street movement.

Under this lens, King Tone could be classified as a knowledge broker, drawing on various ties with members of more successful social 
movements in NYC, including the Young Lords and Blackstone Rangers (Flood 2003), ${ }^{7}$ to direct the ALKQN towards a similar revolutionary trajectory. As a broker, King Tone engaged in two levels or types of brokerage. The first is what Burt (2004: 335) calls the "transferring of best practices," whereby "People familiar with activities in two groups are best able to see how a belief or practice in one group can create value in the other." King Tone saw value in the structure and organizing principles of other grass-roots social movements and utilized that information to promote legitimacy in his own group, translating it into a language easily understood by members of the Latino community (Barrios 2003).

The second level of brokerage occurs when individuals "draw analogies between groups ostensibly irrelevant to one another" (Burt 2004: 355). Burt (2004: 355) argues that, "People who can recognize that the way that other groups think or behave may have implications for the value of operations in their own group, will have an advantage over those who do not." As a broker, King Tone drew analogies between irrelevant groups - e.g., the ALKQN and the U.S. justice system. His considerable contact with the criminal justice system allowed him to broker information about how criminal cases were heard, how sentences of guilt and innocence were determined, and how constitutional rights were handled by the state. As a broker between the judicial system and the ALKQN, he adopted and applied the principles and practices of the former to the latter.

For example, under the leadership of King Tone, internal strife, dissension, and rule breaking were no longer punished on a violent, ad hoc basis; rather, principles of constraint and transparency were used to determine the guilt or innocence of members. Modified versions of habeas corpus, the right to representation, and the right to appeal-guiding principles of the U.S. judicial system - were adopted and applied by the ALQKN's "Crown Council," the group's court system for dealing with internal conflicts. ${ }^{8}$

Zerubavel (1997) offers a different lens for examining the role of leadership in transforming the ALKQN from street gang to street movement. He states that, "We think not only as individuals and as human beings, but also as social beings, products of particular social environments that affect as well as constrain the way we cognitively interact with the

7. All three groups are part of the Chicago gang alliance known as the "People Nation" (Valentine 1995).

8. This is also another example of DiMaggio and Powell's (1983) notion of "mimetic isomorphism," whereby organizations model themselves on other organizations that they perceive to be more legitimate and/or successful. As the ALKQN's bid towards legitimacy increased, so too did the mimicking of more legitimate (often official state) institutions. 
world" (Zerubavel 1997: 15). "As we become socialized and learn to see the world through the mental lenses of particular thought communities," he continues, "we come to assign to objects the same meaning that they have for others around us [...]" (Zerubavel 1997: 15). The ALKQN is one such "thought community," which socializes its members and teaches them to see the world through particular social and cultural lenses. Much of this can be attributed to leadership.

Under King Blood, for example, the ALKQN acted as a mechanism of protection - one that was essential for the survival of the Latino community within the highly segregated and hyper-racialized prison system of the U.S. (Gundur 2020). Attuned to prison culture and the immediate needs of his members, King Blood socialized the rank-and-file into a particular thought community, predicated on survival at all costs - operationalized through acts of violence, ruthlessness, intimidation, hatred towards outsiders, and fear-mongering. As part of this thought community, all rank-and-file members came to see the world through a very particular lens - one that called for the execution of traitors and violence against rival gang members.

King Tone, on the other hand, conscious of the demographic and cultural shifts occurring within the rank-and-file, socialized members to view the world from a markedly different socio-cultural lens. As Brotherton and Barrios (2004: 282) maintain, "To succeed in its newfound quest for respectability and legitimacy, a different way of seeing the world was necessary. The group had to emerge from its focus on internal and local concerns and begin to view itself as reciprocally linked to a larger social and political construct. In order to do this, the group literally needed to be re-educated." It was through the guidance and teachings of King Tone, who was well known within the group as a "moralist" and "true believer" in Kingism (Kontos 2012: 114), that members were resocialized into a new and relatively foreign thought community-one predicated on the empowerment of the Latino community through positive means, including educational attainment, vocational training, and political involvement and activism. To solidify and articulate this new unifying message, he took the next logical organizational step and redrafted both the King's Manifesto and Constitution.

The King's Manifesto, written in highly philosophical language, outlines the overall purpose of the group, which is tied to the doctrine of "Kingism"- an ideology imbued with its own set of prayers, various stages of enlightenment, and clear rules and procedures for what members can and cannot do, both within the organization and in their private lives. It states that, over time, individual members of the ALKQN must forgo criminality and strive towards a state of "enlightenment," 
where they will come to recognize that, "[...] the time for revolution is at hand - a revolution that will bring freedom to our people. The New King is the turning-wheel of change, [...] [and] a fearless seeker of freedom."

The two leaders of the NYC chapter attempted to empower the Latino community through radically different means. Under King Blood, empowerment was promoted through protection, violence against rival gang members and internal dissenters, illicit activities (e.g., drug dealing and extortion), and a strict policy of excluding outsiders (e.g., researchers, people of other racial backgrounds, and non-members). Under King Tone, and in line with the group's transition towards legitimacy and community activism, empowerment was achieved through the promotion of positive activities (e.g., education, employment, and political involvement), the practice of non-violence, and adherence to the principles of fairness and transparency (e.g., openness to the media, researchers, and those of non-Latino origin).

King Tone's religiously infused reading of the King's Manifesto further promoted this new and more positive approach to empowerment. According to Brotherton and Barrios (2004: 147), "King Tone embraced the symbols and parables of religion because he knew that they were effective in communicating to the group's diverse ranks the new personal and organizational politics of the movement and the new expectations of the leadership. Of course, he also knew that many Latin Kings had been raised in the Catholic Church and, therefore, they understood, implicitly, many of the references to which he often referred." This is another example of mimetic isomorphism (DiMaggio and Powell 1983). By adopting the signs, symbols, and teachings of Catholicism, and by holding many of the ALKQN's meetings at a Catholic Church in the Bronx (Barrios 2003), ${ }^{9}$ King Tone managed to steer many members away from criminality and towards a legitimate lifestyle (Richardson 1997).

Changes to the King's Constitution during King Tone's reign also illustrate the group's desire to become (and to be perceived as) a legitimate organization. Under King Tone, the Constitution, which outlines the rules and regulations that govern the daily activities of the Nation, was transformed into a highly bureaucratic document. Knox (2000), for example, states that, "Their written constitution and by-laws reflect the highest level of organizational skill we have seen in any gang anywhere in the world. [The NYC chapter] of the Latin Kings is a gang that emulates a federal bureaucracy in its detail given to policies and procedures and illustrates a high level of sophistication in its micro-management of membership behavior (i.e., standards, guidelines, etc.)."

9. Some of these meetings were attended by one of the authors in 2006 . 
King Tone argued that the ability of the NYC chapter to successfully transform into a legitimate organization would require the bureaucratization of the Constitution and the removal of contested sections, such as those pertaining to torture, execution, and the physical punishment of members..$^{10}$ In fact, the first amendment he made to the Constitution was the abolition of the death penalty, "which ended a notorious chapter in the group's existence. No longer would the group's leaders be able to issue TOS (terminate on sight) instructions to subordinates. This reform removed from the organization one of the principle foundations of a regime of fear, allowing for a much freer atmosphere of reasoned debate, discussion, and innovative strategy development to become the chief characteristics of the new ALKQN" (Brotherton and Barrios 2004: 208).

Similarly, during this transformative period, the group became accessible to outsiders, including community leaders, academics, and the media. In line with its push towards legitimacy, the group's newfound openness meant that:

$[\ldots]$ the actions of the group were much more permeable and subject to both positive and negative judgments. The impact on the organization was dramatic, for now the group could call on outside "experts" for consultation in such areas as leadership development, conflict resolution, fundraising, legal advice, and political strategy, all of which influenced the way the organization saw itself. Thus, as the group's confidence grew in its dealing with outside elements, and as it gained greater visibility, its own organizational practices were transformed as well (Brotherton and Barrios 2004: 209-210).

By the late-1990s, the NYC chapter began to resemble a legitimate, highly formal, and relatively transparent organization characterized by: 1) a strict hierarchy with office holders occupying defined realms of power and paths of both promotion and demotion, 2) decision-making made by elected organizational bodies such as the Crown Council and Supreme Team, 3) a formal membership directory with full biographical records of every member, 4) minutes of group meetings and reports of group activities, and 5) accounts of dues, both owed and spent, which were open to the scrutiny of members (Brotherton and Barrios 2004). Clearly, an observable and fundamental shift had occurred, taking place during an uncertain and unsettled period in the group's history-i.e., dur-

10. Two other examples of changes that King Tone made to the King's Constitution are presented here verbatim: 1) "The use of angel dust, animal tranquilizer, glue, LSD or acid, heroin, and downers is unlawful, and cannot be sold"; 2) "No member shall take the law into their own hands, especially when he knows that what he does will reflect upon the Nation and jeopardize the health and wellbeing of every member of the Nation." 
ing the transitional phase and the transferring of leadership from King Blood to King Tone.

Swidler $(1986 ; 2001)$ focuses primarily on how culture influences action. She defines culture as "a toolkit of symbols, stories, rituals, and world-views, which people may use in varying configurations to solve different kinds of problems" (Swidler 1986: 273). She argues that in periods of transformation, "ideologies - explicit, articulated, highly organized meaning systems - establish new styles and strategies of action. When people are learning new ways of organizing individual and collective action, then doctrine, symbol, and ritual directly shape action" (Swidler 186: 270). Swidler (1986: 279) goes on to state that, "While not perfectly consistent, [cultures in unsettled periods] aspire to offer not multiple answers, but one unified answer to the question of how human beings should live. In conflict with other cultural models, these cultures are coherent because they must battle to dominate the world-views, assumptions, and habits of their members."

During its transitional phase, the culture and practices of the NYC chapter became increasingly coherent in order to dominate the worldviews of its members. A disjointed, unclear, and fractioned ideology would have placed the Nation in competition with other (perhaps more coherent and captivating) cultural models towards which members could have flocked, such as the Neta (another organized street gang in NYC) or religious organizations. Swidler's analysis helps elucidate why the ALKQN took on the coherent and bureaucratic shape that it did, why the shift occurred when it did (i.e., during an unsettled and transitional period in the group's history), and why its cultural ideology drove the group to think and act in particular ways.

DiMaggio and Powell's (1983) mimetic isomorphism is also useful for understanding how the NYC chapter transformed from street gang to legitimate street movement. They maintain that, "Uncertainty is a powerful force that encourages imitation. When the environment creates symbolic uncertainty, organizations may model themselves on other organizations" (DiMaggio and Powell 1983: 151). During its transformative stage, the group entered an unknown field, i.e., the legitimate world of local community politics, and navigating this new and uncertain world pushed King Tone to model the ALKQN after other, more successful street movements. Brotherton and Barrios (2004: 147) illustrate this point succinctly: 
King Tone takes his cues from a number of other social movements. Chief among them are the Black Muslims and the Orthodox Jews. Consequently, Tone sees his "Nation" in a way that is similar to both of these communities that have built strong interdependent social, political, and economic networks from which they are able to demand more power and resources.

DiMaggio and Powell's (1983: 149) coercive isomorphism, defined as a "constraining process that forces one unit in a population to resemble other units that face the same set of environmental conditions," provides an alternative lens for understanding the transition. They argue that, "Coercive isomorphism results from both formal and informal pressure exerted on organizations by other organizations upon which they are dependent and by cultural expectations in the society within which organizations function" (DiMaggio and Powell 1983: 150). Furthermore, "In some circumstances, organizational change is a direct response to government mandate" (DiMaggio and Powell, 1983: 150).

In the decade prior to its transformation, the NYC chapter experienced consistent and intense harassment from the state-particularly from police who arrested members for gangbanging and wearing gang colours (Brotherton and Barrios 2004) and the courts who handed down multiple life sentences to ALKQN leaders (Tabor 1994). The NYC chapter may have undertaken their transition towards legitimacy in response to this pressure - as a way to deflect government scrutiny and survive as an organization. The NYC chapter, in other words, shifted under the formal pressure of the state, which effectively coerced it to transition into a legitimate movement — one that resembled other legitimate organizations.

Phillips and Zuckerman (2001) offer another lens for unpacking the transformation, however temporary, of the NYC chapter. The authors illustrate that an actor's status within an organizational field (or interface) influences action. Conformity to the status quo is high at the middle of a status order and low at either end. Since high status actors like King Tone are "confident in their social acceptance, they are emboldened to deviate from conventional behavior" (Phillips and Zuckerman 2001: 380). This explains his ability to initiate an organizational turning point, taking a street gang and steering it in an entirely different direction. Similarly, low status actors, e.g., gangbangers and ex-convicts, "feel free to defy accepted practices because they are excluded regardless of their actions" (Phillips and Zuckerman 2001: 380); whether they conform or not has little impact on their status, given their position at the bottom of the status order.

Within this interface, middle status actors-i.e., those who are insecure in their position - are most eager to integrate and, thus, most likely to conform (Phillips and Zuckerman 2001). This explains why 
the NYC chapter reverted back to its street gang tendencies after the arrest of King Tone. As a high status actor, he directed the group and elicited support from middle status actors, i.e., those who "value their membership in a group, yet, feel insecure in that membership" (Phillips and Zuckerman 2001: 380). After his incarceration, and without strong leadership to sustain the transformation, middle status actors snapped back towards the group's historical status quo, taking the organization along with them.

Between 1995 and 1998, the NYC chapter of the ALKQN transformed from street gang to street movement-from a notorious player in NYC's underworld to a rising star in the community services sector in the city's barrios. In its short time as a legitimate organization, the group worked hard to create positive change at the local level, building playgrounds in disadvantaged communities, setting up scholarship funds to help Latino youth attend college, and handing out food vouchers to help local residents in need (Brotherton and Barrios 2004). However, in May 1998, after two-plus years of intense media attention and public scrutiny (Kontos 2012), the NYC chapter was dismantled by law enforcement, marking the second and final organizational turning point in the Bloodline's history - a sudden end to its push towards legitimacy and a reversion back to its gang tendencies and practices.

\section{Street Gang or Street Movement? A Muddled Future}

On May $14^{\text {th }}, 1998$, approximately 1000 members of the FBI, NYPD, and DEA launched a pre-dawn raid on the NYC chapter of the ALKQN, arresting ninety-two suspected members of the organization. Among those arrested were King Tone and other high-ranking leaders. King Tone was charged with a number of drug related offences; he appeared in federal court in 1999, where he pled guilty to "conspiracy to sell and distribute heroin" during the summer of 1996, just months after becoming leader of the NYC chapter and a year before the group's move towards legitimacy. He was sentenced to thirteen years in federal prison, the first three of which were served in solitary confinement (Brotherton and Barrios 2004).

Undoubtedly, the dismantling of the Nation's leadership created a large hiccup in the chapter's progression towards legitimacy. In fact, the conviction and incarceration of King Tone is often cited as the major factor leading to the group's regression back into a street gang (Brotherton and Barrios 2004). However, other factors - namely the constraining effects of categories on action (Zuckerman 1999) and the difficulties associated with crossing categorical boundaries (Rao et al. 2005) - may 
have also contributed to the Nation's inability to maintain its status as a legitimate street movement.

The work of Zuckerman (1999) examines how categories and classifications (e.g., legitimate and illegitimate, classifiable and unclassifiable) influence an actor's success or failure within a given field or industry. The major players in this conceptual drama are candidates and critics. The author argues that, "Social objects are evaluated via legitimate categories. New roles and types emerge with difficulty as actors face pressure to demonstrate that they conform to recognized 'types.' In general, actors accede to this categorical imperative" (Zuckerman 1999: 13981399). However, when this does not occur, actors become unclassifiable by critics and suffer various penalties. Failure to be classified as intelligible (and thus legitimate) creates confusion over an actor's identity; in short, it reduces their appeal within a given field. The inability of actors to manage their market identity within a given field is what Zuckerman (1999) calls "coverage mismatch," defined as the extent to which an actor operating in a particular industry is not classified as legitimate by the critics who specialize in that industry (Zuckerman 1999).

Despite its best efforts to transform and become part of the community services sector, the NYC chapter failed to be classified as a "legitimate" or full-fledged actor by critics-i.e., NGOs, politicians, police, and the media (Kontos 2012). In other words, it was unable to manage its market identity, which made it unintelligible and illegitimate to critics in the field. As Kontos (2012: 115) explains, even during its foray into the legitimate sphere, the NYC chapter "could not easily extricate itself from gangland. It had an image to maintain among its rivals and enemies, where it could not afford to be seen as weak, even as it tried to change its image in its dealings with the community and the larger public." This public image, which oscillated between moral and immoral, legitimate and illegitimate, diluted its market identity and ultimately reduced its ability to gain resources and sustain itself as a legitimate organization, especially after King Tone's incarceration.

Rao et al. (2005) offer an equally compelling lens for understanding the transformation and ultimate regression of the NYC chapter. The authors analyze the erosion of categorical boundaries in the case of opposing category pairs, arguing that: 1) "categorical boundaries weaken when the borrowing from a rival category by high-status actors triggers emulation"; 2) "high status actors have leeway in how much they should conform to the conventions of a genre, and can innovate through crosscategory borrowing and still be protected against accusations that they are not authentic"; 3) "penalties to borrowing by critics exist, but decline as the number of peers who borrow increases," and; 4) "actors can re- 
draw the boundaries of categories, which critics will often recognize" (Rao et al. 2005: 968, 972).

During its transformation from street gang to street movement, the NYC chapter was operating in two opposing categories - the illegitimate and legitimate world. It attempted to cross categorical boundaries, drawing on and acquiring techniques and structures from the legitimate world and applying them in the illegitimate sphere. Initially, under the guidance and encouragement of King Tone, a high status actor in the world of street gangs, the NYC chapter made progress in breaking down the boundaries between these two juxtaposed categories - resembling a hybrid between informal street gang and formal organization. The critics (i.e., police, politicians, and the media) did not initially penalize them for this unorthodox undertaking. However, New York City was quickly becoming what Kontos (2012: 116) calls "an unforgiving place" and "a test site for the theory of Broken Windows," with the NYPD cracking down on petty offenses and targeting inner-city residents and gang members alike. The critics eventually ceased their support of (or stopped being indifferent towards) the categorical boundary crossing; instead, they began penalizing it — enforcing the rigid line between legitimate and illegitimate spheres. The inability of the NYC chapter to break down these opposing categorical boundaries may have played a role in its fall back into criminality.

The initial success of the NYC chapter in breaking down the barriers between legitimate and illegitimate spheres should not be surprising, given their position as a high status actor in the gangland interface. However, as Rao et al. (2005) maintain, to sustain this erosion and avoid penalization, lower status actors must follow suit and emulate these actions. The inability of the NYC chapter to permanently break down boundaries may have been due, in part, to the inability (or unwillingness) of other street gangs to follow along with this categorical bricolage. As Rao et al. (2005: 972) note, "[...] penalties to borrowing by critics exist, but decline as the number of peers who borrow increases." If other street gangs had adopted this process of boundary crossing, and also started to transition into legitimate organizations, then the willingness and ability of critics to prevent this type of behavior would have likely decreased. Both conceptual lenses, in very different ways, explain the same phenomenon - the inability of the NYC chapter to maintain its street movement trajectory. 


\section{Conclusion}

Most contemporary studies on street gangs provide snapshots into the social and economic worlds these groups inhabit. Sociologists and criminologists have long documented the conditions giving rise to gang formation or disbandment, while economists have contributed detailed accounts of the organization of criminal markets, the economic impact of criminal groups on society, the financial structuring of gangs (Levitt and Venkatesh 2000), and the internal governance institutions of violent and profitable criminal organizations (Leeson 2007; Leeson and Skarbek 2010) (see Fiorentini and Peltzman (1995) for a comprehensive set of essays on the economics of criminal organizations). However, surprisingly little attention has been paid to how these groups evolve over the life course.

Our analysis demonstrates that street gangs are complex and fluid organisms that change over time and space - be it in response to gradual shifts in their environment or sudden and dramatic events that lead to organizational turning points. In the case of the NYC chapter of the ALKQN, both types of changes contributed to transformations in organizational structure, purpose, and practices over time.

On a much broader level, we believe that our analysis offers important insights for both scholars and practitioners. While the concept of turning points has been used to understand criminal careers and desistance from crime among individuals - e.g., Benson (2001); Sampson and Laub (1993, 2005) - criminologists have not explored organizational turning points as a way for understanding shifts in criminal groups. The applicability of this concept, however, goes beyond street gangs; it can be used to understand the trajectory of outlaw motorcycle clubs and mafia clans, as well. ${ }^{11}$ Similarly, organizational turning points can be useful for scholars studying criminal justice organizations, such as the police and corrections. It can help explain sudden shifts in the outlook, structure, and practices of these legitimate organizations in response to dramatic and often public events - e.g., high profile shootings of civilians or police officers. We encourage future researchers to identify organizational turning points in these various organizations, from state institutions to street gangs, and test the explanatory power of the concept across settings.

11. From a sociological perspective, the concept of organizational turning points may also be of value in explaining the trajectory of noncriminal organizations - be it a corporation, small business, or even a household. The discovery of infidelity by a spouse, for example, may lead to a sudden and drastic change in the dynamics or structure of a family unit. Similarly, the acquisition of funding by a small start-up company may result in its sudden and rapid growth and success. 
On a more practical level, criminal justice agencies would significantly benefit from learning to identify organizational turning points and responding to them accordingly. In the case of the NYC chapter of the ALKQN, law enforcement interventions helped to remove the violent and erratic King Blood, providing space for the group to change directions. Yet, the arrest and removal of King Tone had significant and negative backlashes - not only for the ALKQN, but also for the NYPD's effort to fight crime more broadly. King Tone's removal was a major factor in the group's implosion and subsequent return to criminality. While it may seem counter-intuitive to suggest that law enforcement agencies pay close attention to (or even cooperate and coordinate with) gang leaders when planning interventions, such an approach may actually have more positive and long-lasting outcomes from a crime-prevention perspective.

Some may believe that the final chapter of the ALKQN's history has been written. We are inclined to disagree. The NYC chapter has demonstrated that it can and does capitalize on short- and long-term opportunities to transform, adapting and growing in ways that allow for their continued relevance and survival. The question, therefore, is not whether the ALKQN will survive the coming years, but rather, what form it will take next.

\section{REFERENCES}

Barrios, Luis. 2003. "The Almighty Latin King and Queen Nation and the spirituality of resistance: Agency, social cohesion, and liberating rituals in the making of a street organization." In: Kontos, Louis, David Brotherton and, Luis Barrios (eds.) Gangs and Society: Alternative Perspectives. New York, NY: Columbia University Press, 119-135.

Benson, Michael L. 2001. Crime and the life course: An Introduction. Los Angeles, CA: Roxbury.

Block, Carolyn R., and Richard Block. 1993. Street Gang Crime in Chicago. Research in Brief, National Institute of Justice, Office of Justice Programs, U.S. Department of Justice.

Brotherton, David. 2013. "Latin Kings.” In: Ross, Jeffrey I. (eds.) Encyclopedia of Street Crime in America. Thousand Oaks, CA: Sage Publications, pp. 236-240.

Brotherton, David. 2015. Youth Street Gangs: A Critical Appraisal. New York, NY: Routledge.

Brotherton, David, and Luis Barrios. 2004. The Almighty Latin King and Queen Nation. New York, NY: Columbia University Press.

Bucerius, Sandra. 2014. Unwanted: Muslim Immigrants, Dignity, and Drug Dealing. New York, NY: Oxford University Press. 
Burt, Ronald. 2004. "Structural holes and good ideas." American Journal of Sociology 110(2): 349-399.

Calvo, Alex. 2015. "Latino gangs in Catalonia: Latest police operations expose extent of the problem, signal policy shift." Small Wars Journal (accessed 15 December 2016).

Carrillo, Juan D., and Denis Gromb. 2007. "Cultural inertia and uniformity in organizations." The Journal of Law, Economics and Organization 23(3): 743-771.

Contreras, Randol. 2013. The Stickup Kids: Race, Drugs, Violence, and the American Dream. Berkeley, CA: University of California Press.

Curtis, Ric. 2003. "The negligible role of gangs in drug distribution in New York City in the 1990s." In: Kontos, Louis, David Brotherton, and Luis Barrios (eds.) Gangs and Society: Alternative Perspectives. New York, NY: Columbia University Press, 41-61.

Coles, Nigel. 2001. "It's not what you know-It's who you know that counts. Analysing serious crime groups as social networks." British Journal of Criminology 41(4): 580-594.

Decker, Scott H., and Berrick van Winkle. 1996. Life in the Gang: Family, Friends, and Violence. New York, NY: Cambridge University Press.

DeKeseredy, Walter S., and Molly Dragiewicz. 2011. The Routledge Handbook of Critical Criminology. London: Routledge.

Dezalay, Yves. 1990. "The big bang and the law." Theory, Culture and Society 7(2-3): 279-293.

DiMaggio, Paul, and Walter W. Powell. 1983. "The iron cage revisited: Institutional isomorphism and collective rationality in organizational fields." American Sociological Review 48(2): 147-160.

Dobbin, Frank, and Timothy Dowd. 2000. "The market that antitrust built: Public policy, private coercion, and railroad acquisitions, 1825-1922." American Sociological Review 65(5): 635-657.

Emirbayer, Mustafa, and Victoria Johnson. 2008. "Bourdieu and organizational analysis." Theory and Society 37(1): 1-44.

Feixa, Carles, Noemi Cannelles, Laura Porzio, Carolina Recio, and Luca Gilberti. 2008. "Latin Kings in Barcelona." In: van Gemert, Frank, Dana Peterson, and Inger-Lise Lien (eds.) Street Gangs, Migration and Ethnicity. Devon: Willan Publishing, 63-78.

Fiorentini, Gianluca and Sam Peltzmann (eds.) 1995. The Economics of Organised Crime. Cambridge: Cambridge University Press.

Flood, Richard M. 2003. "Towards a theory of revolutionizing street nations." Socialism and Democracy 17(1): 245-253.

Fraser, Alistair. 2015. Urban Legends: Gang Identity in the Post-Industrial City. Oxford: Oxford University Press. 
Gundur, Rajeev V. 2020. "Negotiating violence and protection in prison and on the outside: The organizational evolution of the transnational gang Barrio Azteca." International Criminal Justice Review 30(1): 30-60.

Hser, Yih-Ing, Douglas Longshore, and M. Douglas Anglin. 2007. "The life course perspective on drug use: A conceptual framework for understanding drug use trajectories." Evaluation Review 31(6): 515-547.

Kellogg, Katherine C. 2009. "Operating room: Relational spaces and microinstitutional change in survey." American Journal of Sociology 115(3): 657711.

Knox, George W. 2000. Gang Profile: The Latin Kings. Available at: www.ngcrc. com/ngcrc/page15.htm (accessed 14 December 2016).

Kontos, Louis. 2012. "Gangs, politics and media: Lessons from the New York chapter of the Almighty Latin King and Queen Nation." In: Bissler, Denise L., and Joan L. Conners (eds.) The Harms of Crime Media: Essays on the Perpetuation of Racism, Sexism and Class Stereotypes. Jefferson: McFarland and Company, 111-126.

Kontos, Louis, David Brotherton, and Luis Barrios (eds.). 2003. Gangs and Society: Alternative Perspectives. New York, NY: Columbia University Press.

Leeson, Peter T. 2007. "An-arrgh-chy: The law and economics of pirate organization." Journal of political economy 115(6): 1049-1094.

Leeson, Peter T., \& Douglas B. Rogers. 2012. "Organizing crime.” Supreme Court Economic Review 20(1): 89-123.

Leeson, Peter T., \& David B. Skarbek. 2010. "Criminal constitutions." Global Crime 11(3): 279-297.

Levitt, Steven D. and Sudhir A.Venkatesh. 2000. "An economic analysis of a drug-selling gang's finances.” Q.J.E 15 (August): 755-89.

Martinez, Juan F.E. 2003. "Urban street activists: gang and community efforts to bring peace and justice to Los Angeles neighborhoods." In: Kontos, Louis, David Brotherton and Luis Barrios (eds.) Gangs and Society: Alternative Perspectives. New York, NY: Columbia University Press, 95116.

Merton, Robert. 1938. "Social structure and anomie." American Sociological Review 3(5): 672-682.

Papachristos, Andrew V., David M. Hureau, and Anthony A. Braga. 2013. "The corner and the crew." American Sociological Review 78(3): 417-447.

Palmas, Luca Q. (eds.) 2010. Atlantico Latino: Gang Giovanili e Culture Transnazionali. Rome: Carocci Editore.

Pattillo, Mary E. 1998. "Sweet mothers and gangbangers." Social Forces 76(3): 747-774.

Phillips, Damon J., and Ezra W. Zuckerman. 2001. "Middle status conformity." American Journal of Sociology 107(2): 379-429. 
Portes, Alejandro, and Steven Schafer. 2006. Revisiting the Enclave Hypothesis: Miami 25 Years Later. Princeton: The Center for Migration and Development, CMD Working Paper \#06-10.

Rao, Hayagreeva, Philippe Monin, and Rodolphe Durand. 2005. "Border crossing: Bricolage and the erosion of categorical boundaries in French gastronomy." American Sociological Review 70(6): 968-991.

Richardson, J.H. 1997. “The Latin Kings.” New York Magazine (accessed 15 Dec 2016).

Sampson, Robert J., and John H. Laub. 1993. Crime in the Making: Pathways and Turning Points Through Life. Cambridge, MA: Harvard University Press.

Sampson, Robert J., and John H. Laub. 2005. "A life-course view of the development of crime." Annual American Academy of Social Sciences 602: $12-45$.

Sampson, Robert J., Stephen W. Raudenbush, and Felton Earls. 1997. "Neighborhoods and violent crime: A multilevel study of collective efficacy." Science 227(5328): 918-24.

Sanchez-Jankowski, Martin. 2003. "Gangs and social change." Theoretical Criminology 7(2): 191-216.

Sauder, Michael, and Wendy N. Espeland. 2009. "The discipline of rankings: Tight couplings and organizational change." American Sociological Review 74(1): 63-82.

Swidler, Ann. 1986. "Culture in action: Symbol and strategies." American Sociological Review 51(2): 273-286.

Swidler, Ann. 2001. Talk of Love: How Culture Matters. Chicago, IL: University of Chicago Press.

Sykes, Gresham M., and David Matza. 1957. "Techniques of neutralization." American Sociological Review 22(6): 664-670.

Tabor, Mary B.W. 1994. "20 Members of Hispanic Gang Indicted in Multiple Killings." The New York Times (accessed 14 December 2016).

Teruya, Cheryl, and Yih-Ing Hser. 2010. "Turning points in the life course: Current findings and future directions in drug use research." Current Drug Abuse Review 3(3): 189-195.

Valentine, Bill. 1995. Gang Intelligence Manual: Identifying and Understanding Modern-Day Violent Gangs in the United States. Boulder: NCJRS.

Venkatesh, Sudhir A. 1997. "The social organization of street gang activity in an urban ghetto." American Journal of Sociology 103(1): 82-111.

Venkatesh, Sudhir A. 2000. American Project. Chicago, IL: University of Chicago Press. 
Venkatesh, Sudhir A. 2008. Gang Leader for a Day. New York, NY: The Penguin Press.

Vigil, James D. 2003. "Urban violence and street gangs." Annual Review of Anthropology 32: 225-242.

Zerubavel, Eviatar. 1997. Social Mindscapes. Cambridge, MA: Harvard University Press.

Zuckerman, Ezra W. 1999. "The categorical imperative." American Journal of Sociology 104(5): 1398-1438.

Luca Berardi is an Assistant Professor of Sociology and Social Psychology at McMaster University. He is a criminologist and urban ethnographer interested in the relationship between poverty, violence, and victimization in social housing and in prison. He is currently studying the impact of the opioid epidemic on police services and carceral institutions. Dr. Berardi is a collaborator on the University of Alberta Prison Project, has published in City \& Community and Qualitative Sociology, and is co-editor of the Oxford Handbook on Ethnographies of Crime and Criminal Justice.

Email:berardil@mcmaster.ca

Dr. Sandra M. Bucerius is an Associate Professor of Sociology and Criminology in the Department of Sociology at the University of Alberta. Bucerius deploys extensive qualitative and ethnographic research to reveal the intricacies of settings that are difficult both to access and understand: prisons, police organizations, and marginalized street and newcomer communities. Bucerius is the Director of the University of Alberta Prison Project. Bucerius has published three books with Oxford University Press and is Co-editor of the Oxford University Press Handbook series in Criminology (with Michael Tonry). She also serves on the advisory board of Criminology and is an Executive Member of the Canadian Research Network of Terrorism, Security, and Society (TSAS). She is also on the advisory board for immigration related questions in Germany (Rat fuer Migration).

Email: bucerius@ualberta.ca 
168 C) Canadian Journal of Sociology/Cahiers Canadiens de Sociologie 45(2) 2020 